\title{
Переходные процессы при токовой перегрузке в цепи переменного тока с ВТСП-проводом
}

\author{
() В.А. Мальгинов ${ }^{1}$, А.В. Мальгинов ${ }^{1}$, Л.С. Флейшман ${ }^{2,3}$ \\ ${ }^{1}$ Физический институт им. П.Н. Лебедева РАН, Москва, Россия \\ ${ }^{2}$ Энергетический институт им. Г.М. Кржижановского, Москва, Россия \\ ${ }^{3}$ Российский государственный геологоразведочный университет им. С. Орджоникидзе, Москва, Россия \\ E-mail: malginovva@lebedev.ru
}

Поступило в Редакцию 26 декабря 2018 г.

В окончательной редакции 26 декабря 2018 г.

Принято к публикации 10 января 2019 г.

Установлено, что потеря сверхпроводимости в ВТСП-проводах при токовой перегрузке на переменном токе сопровождается изменением знака разности фаз между током и напряжением. В стабилизированном ВТСП-проводе второго поколения при перегрузке обнаружены колебания амплитуд переменного тока и напряжения, обусловленные колебаниями размера нормальной зоны в сверхпроводящем слое. Изменение знака разности фаз может быть использовано для своевременной регистрации возникновения нормальной зоны в токонесущих элементах сверхпроводникового электрооборудования.

DOI: 10.21883/PJTF.2019.07.47532.17657

С целью применения высокотемпературных сверхпроводников (ВТСП) в электроэнергетике [1] были созданы опытные образцы силовых кабелей [2,3] и трансформаторов [4] на основе ВТСП-проводов как первого $(1 G)$, так и второго $(2 G)$ поколения. Использование подобного ВТСП-оборудования в электрических сетях возможно только при условии обеспечения требуемой надежности его работы в различных режимах. Это особенно актуально в случае токовой перегрузки в аварийном режиме, когда протекающий по ВТСП-проводам ток превышает их токонесущую способность. Существует необходимость создания и применения специальных систем защиты, основанных на принципе обнаружения зарождения нормальной зоны в сверхпроводящих токонесущих элементах (ТНЭ) [5].

Сложность обнаружения нормальной зоны в ТНЭ действующего электроэнергетического ВТСП-устройства обусловлена, во-первых, наличием в нем высокого напряжения. Это не позволяет (во избежание электрического пробоя) размещать электрические зонды и температурные датчики непосредственно на ТНЭ. Во-вторых, активная составляющая падения напряжения на ВТСПтоконесущих элементах при потере сверхпроводимости имеет малую величину вследствие наличия как медного стабилизирующего слоя и/или серебряной матрицы в ВТСП-проводах, так и защитного медного шунта большого сечения в центральном формере ВТСП-кабеля [2]. Поэтому задача создания методов своевременного обнаружения потери сверхпроводимости в ВТСП-проводах при токовой перегрузке является весьма важной.

Поведение ВТСП-проводов в перегруженном режиме определяется главным образом характером теплоотвода в жидкий азот. В [6,7] сообщается о наблюдении нерегулярностей/неустойчивостей при измерениях вольтамперных характеристик (BАХ) $1 G$ ВТСП-проводов на постоянном токе. Авторы указанных работ связывают обнаруженные особенности BAX с изменением характера теплопередачи в жидкий азот, тем более что в [6] аналогичный эффект наблюдался также для медных проводов в жидком азоте. В [8] исследована динамика изменения сопротивления и температуры $1 G$ - и $2 G$-проводов при пропускании через них импульсов постоянного тока. Полученные результаты объяснены изменением механизма отвода тепла при переходе от конвекции к пузырьковому кипению. Явление гистерезиса теплоотвода в области перехода от конвекции к пузырьковому кипению, характерное как для криогенных, так и для обычных жидкостей, описано, например, в [9,10]. О наблюдении нерегулярностей ВАХ на переменном токе в стабилизированных $2 G$ ВТСП-лентах при относительно небольшом превышении критического тока сообщается в $[11,12]$. Электроэнергетические устройства работают главным образом на переменном токе, чем обусловлен значительный интерес к детальному исследованию неустойчивостей в ВТСП-проводах на переменном токе, в том числе на предмет выявления признаков потери сверхпроводимости для использования их в системах мониторинга и противоаварийной защиты.

В настоящей работе приведены основные результаты исследований $\mathrm{BAX}$ и переходных процессов в цепи переменного тока с ВТСП-проводами, охлаждаемыми жидким азотом, в режиме токовой перегрузки.

Образцы для исследований изготавливались из ленточных ВТСП-проводов [1]: $1 G$-проводов производства Sumitomo Electric (ширина $4 \mathrm{~mm}$, толщина $0.2 \mathrm{~mm}$, критический ток при $77 \mathrm{~K}$ около $200 \mathrm{~A})$ и $2 G$-проводов производства SuperPower (ширина $12 \mathrm{~mm}$, толщина медного стабилизирующего слоя с каждой стороны ленты $10 \mu \mathrm{m}$, критический ток при $77 \mathrm{~K}$ около 300 А). 


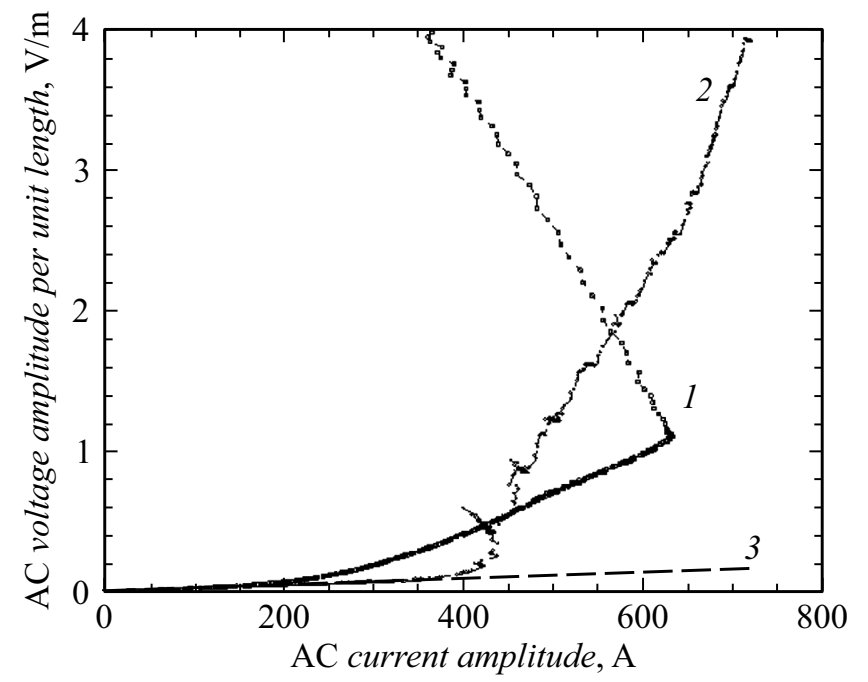

Рис. 1. Амплитудные ВАХ для $1 G$ - $(1)$ и $2 G$-проводов (2). Кривая 3 - экстраполяция сверхпроводящего участка $\mathrm{BAX}$ с индуктивным и контактным сопротивлениями.

Для экспериментального исследования электрических процессов в ВТСП-лентах была применена методика измерений на переменном токе частотой $50 \mathrm{~Hz}$ [13]. Для моделирования реальных условий мониторинга состояния токопроводящей жилы силового ВТСП-кабеля зонды для измерения напряжения размещались на токовых вводах вблизи концов провода. Схема цепи для измерений на переменном токе была построена так, что при возникновении в ВТСП-проводе резистивного состояния ток в цепи определялся сопротивлением провода, несмотря на его низкоомность, обусловленную наличием слоя стабилизатора. Такая схема имитирует поведение ВТСП-устройства в электрической сети при коротком замыкании нагрузки, а для еe реализации ВТСП-провод включался во вторичную цепь понижающего трансформатора, первичная обмотка которого запитывалась автотрансформаторным источником.

На рис. 1 приведены амплитудные ВАХ образцов $1 G$ (кривая 1$)$ и $2 G$ (кривая 2) ВТСП-проводов. Они содержат ряд характерных участков $[11,12]$. Это в первую очередь сверхпроводящий участок при токах, меньших критического, линейность которого обусловлена индуктивным сопротивлением ленты и активным сопротивлением токовых контактов (кривая 3). Затем следует участок с возрастанием крутизны, отвечающий резистивному состоянию сверхпроводника. После него идет „обратный“ участок с потерей сверхпроводимости вследствие теплового срыва (кривая 1) (на кривой 2 этот участок не показан из-за примененного на рисунке масштаба, который необходим для рассмотрения на кривой 2 области вблизи критического тока).

У образца $1 G$ ВТСП-ленты (кривая 1 ) ВАХ в резистивной области имеет монотонный характер, в случае $2 G$ ВТСП-ленты (кривая 2) при амплитудах тока и средней напряженности электрического поля около $430 \mathrm{~A}$ и $0.4 \mathrm{~V} / \mathrm{m}$ соответственно имеется нерегулярность. В [11] было выдвинуто предположение, что она обусловлена перегревом вследствие упомянутой выше смены механизма теплоотвода. В случае $1 G$-провода такого перегрева не происходит предположительно по следующей причине. Даже на постоянном токе для этого требуется на порядок большее время, чем для $2 G$-провода [8]. На переменном же токе в резистивном состоянии, когда тепловыделение происходит лишь в течение небольшой части периода [14], переход к пузырьковому кипению и соответствующий тепловой баланс наступают быстрее, чем произойдет значительный нагрев $1 G$-провода.

Нерегулярность на ВАХ $2 G$ ВТСП-образцов является следствием возникновения и развития неустойчивости на временны́х развертках напряжения и тока, характерный вид которых приведен на рис. 2. На участке $A B$ амплитуда тока не превышает критическую, а напряжение обусловлено в основном индуктивностью ленточного провода. На участке $B C$ осуществлялось повышение питающего напряжения, приводящее к повышению тока в ВТСП-проводе до значения, несколько превышающего (около 30\%) критический ток. При этом напряжение на образце возрастает почти на порядок. После момента времени $C$ изменение питающего напряжения прекращалось, а переходные процессы в цепи происходили только в результате изменения состояния ВТСП-провода. Как следует из рис. 2, переход к установившимся значениям тока и напряжения реализуется посредством колебательного процесса. Последующее повышение питающего напряжения приводит к происходящему регулярным образом (без неустойчивостей) увеличению тока и напряжения на образце (рис. 1, кривая 2).

В силу нелинейности ВАХ ВТСП-проводов в резистивном состоянии напряжение на них является несинусоидальным [14]. При этом фазовые соотношения между током и напряжением можно наиболее наглядным образом определить, отложив их мгновенные значения в соответствующих координатных осях. Вследствие наличия разности фаз получаемые за один период кривые в координатах ток-напряжение имеют вид петель (рис. 3, петли сдвинуты вдоль вертикальной оси). При этом направление движения вдоль петли по часовой стрелке означает, что напряжение опережает ток по фазе; в обратном направлении напряжение отстает от тока. Петли 1-4 получены на $2 G$-проводе, петля $5-$ на $1 G$ проводе. Петля 1 имеет место при токах, меньших критического, и соответствует преобладанию опережающей (индуктивной) составляющей напряжения с небольшой активной (контактной) составляющей. Петли 2-5 получены при токах, превышающих критический, поэтому ветви этих петель на краях сближаются вследствие наличия активного сопротивления провода при максимальном токе в каждом полупериоде. В области колебательного процесса (рис. 2), там, где амплитуда тока максимальна (точка 2 на рис. 2), и в установившемся состоянии (точка 4 на рис. 2) напряжение опережает ток (рис. 3, кривые 2 и 4 соответственно), т.е. доминирует 


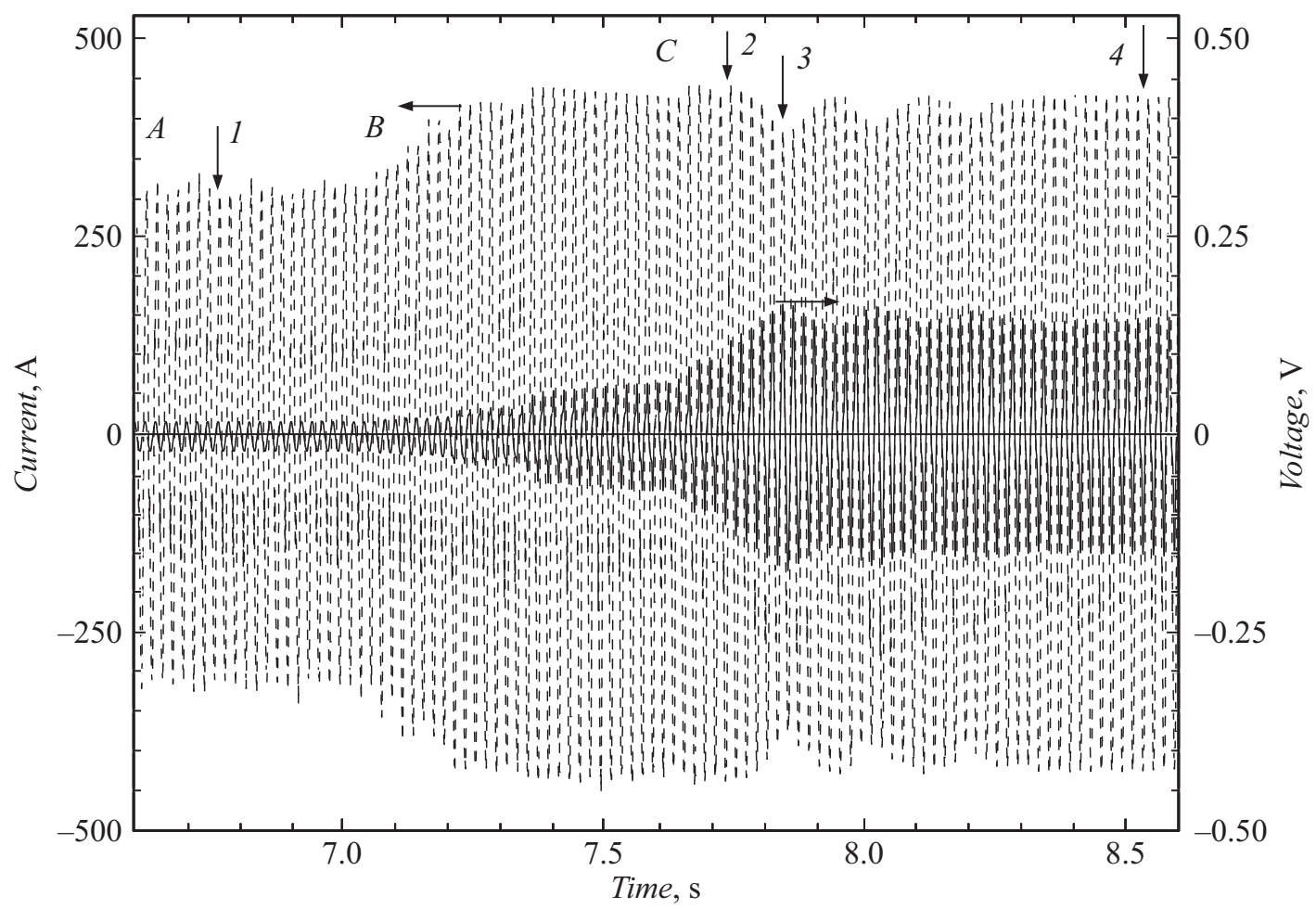

Рис. 2. Временны́е развертки тока и напряжения с колебательным переходным процессом в цепи с $2 G$ ВТСП-проводом. Пояснение в тексте.

индуктивное сопротивление провода при прохождении тока через нуль. При минимуме амплитуды тока и (одновременно) максимуме амплитуды напряжения (точка 3 на рис. 2) движение по петле происходит против часовой стрелки (рис. 3, кривая 3). Это означает, что фазовые соотношения в цепи с $2 G$ ВТСП-проводом для этих временны́х интервалов и вблизи прохождения тока через нуль противоположны соотношениям, характерным для цепи с индуктивным сопротивлением. Самопересечения на кривой 3 (рис. 3) обусловлены появлением высших гармоник напряжения вследствие нелинейности ВАХ ВТСП-провода. Для $1 G$-провода петля в стабильном перегруженном режиме $[11,14]$ соответствует индуктивному сопротивлению вблизи нуля тока с возрастанием активной компоненты при максимумах тока (рис. 3, кривая 5). При превышении тока теплового срыва (около $630 \mathrm{~A})$ и появлении нормального участка на ВАХ образца $1 G$-провода (рис. 1 , кривая 1 ) направление движения по петле в координатах ток-напряжение изменяется и становится аналогичным наблюдаемому на кривой 3 (рис. 3 ).

Таким образом, обнаружено, что при возникновении тепловой и электрической неустойчивости резистивного состояния стабилизированного $2 G$ ВТСП-провода с переменным током при токовой перегрузке возникают колебания амплитуд тока/напряжения и разности фаз между ними. Эти явления могут быть обусловлены периодическим изменением температуры и размера нормальной зоны в ВТСП-слое. Эксперименты показали,

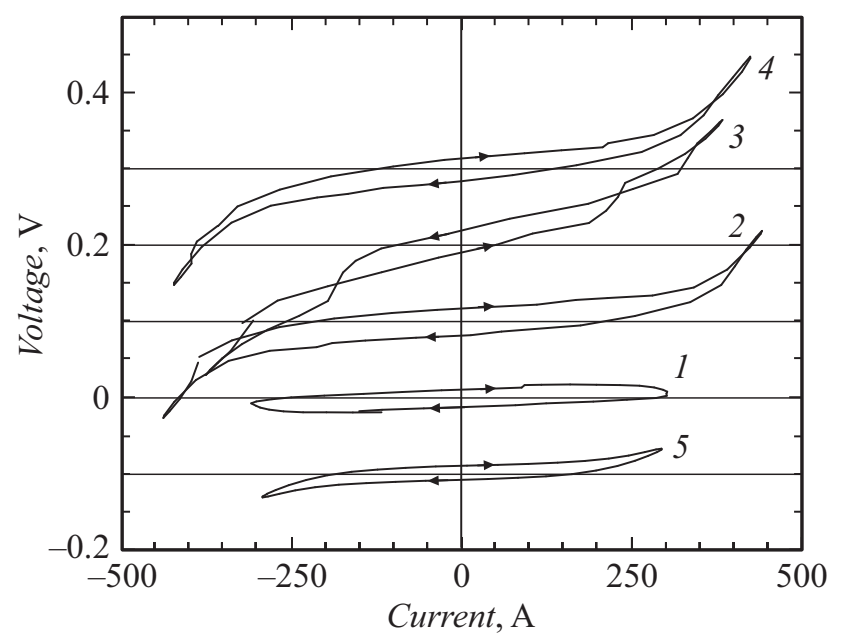

Рис. 3. Мгновенные значения сигналов в координатах ток-напряжение в течение одного периода при различных токовых нагрузках. 1-4 - для $2 G$ ВТСП-провода, 5 для $1 G$ ВТСП-провода. Цифрами 1-4 обозначены кривые, соответствующие моментам времени, указанным стрелками на рис. 2. Кривые 1-5 приведены со сдвигом вдоль оси ординат.

что в резистивном состоянии $1 G$-проводов такой эффект не наблюдается, но при переходе в нормальное состояние происходит изменение знака разности фаз и монотонный рост сопротивления нормальной зоны. Изменение разности фаз между током и напряжением 
при возникновении нормальной зоны в ВТСП-проводах может быть использовано для разработки методики своевременной регистрации потери сверхпроводимости в ТНЭ электроэнергетических устройств без применения в них электрических и температурных зондов.

Работа выполнена на оборудовании ЦКП ФИАН при финансовой поддержке программы фундаментальных исследований Президиума РАН „Фундаментальные проблемы высокотемпературной сверхпроводимости“ и РФФИ в рамках научного проекта № 17-29-10003.

\section{Список литературы}

[1] Superconductors in the power grid: materials and applications / Ed. C. Rey. Cambridge: Elsevier, 2015. 437 p. DOI: 10.1016/B978-1-78242-029-3.00009-1

[2] Волков Э.П., Флейшман Л.С., Высочкий В.С., Носов А.А., Костюк В.В., Фирсов В.П., Осетров С.Ф., Киселев А.Н. Создание и испытание ВТСП КЛ переменного тока длиной 200 м на напряжение 20 кВ с током 1500 А // Инновационные технические решения в программе НИОКР ПАО „ФСК ЕЭС“. Сб. статей. М.: АО „НТЦ ФСК ЕЭС“, 2016. C. 32-49.

[3] Зубко В.В., Высочкий В.С., Фетисов С.С., Носов А.А., Занегин С.Ю. // Электричество. 2014. № 4. С. 24-33.

[4] Волков Э.П., Джсафаров Э.А., Флейшман Л.С., Высочкий В.С., Суконкин В.В. // Изв. РАН. Энергетика. 2016. № 5. C. $45-56$.

[5] Глебов И.А., Шахтарин В.Н., Антонов Ю.Ф. Проблема ввода тока в сверхпроводниковые устройства. Л.: Наука, 1985. C. 25.

[6] Chovanec F., Usak P. // Cryogenics. 2002. V. 42. N 9. P. 543546. DOI: 10.1016/S0011-2275(02)00074-7

[7] Usak P. // Supercond. Sci. Technol. 2003. V. 16. N 4. P. 459 463. DOI: $10.1088 / 0953-2048 / 16 / 4 / 307$

[8] Fetisov S.S., Vysotsky V.S., Zubco V.V. // IEEE Trans. Appl. Supercond. 2011. V. 21. N 3. P. 1323-1327.

DOI: 10.1109 /TASC.2010.2093094

[9] Frost $W$. Heat transfer at low temperatures. N.Y.: Springer Science, 1975. P. 127.

[10] Григорьев В.А., Павлов Ю.М., Аметистов Е.В. Кипение криогенных жидкостей. М.: Энергия, 1977. С. 51.

[11] Мальгинов В.А., Мальгинов А.В., Флейшман Л.С., Ракитин А.С. // ЖТФ. 2017. Т. 87. В. 10. С. 1509-1517. DOI: 10.21883/JTF.2017.10.44995.2077

[12] Мальгинов В.А., Мальгинов А.В., Горбунова Д.А. // ЖТФ. 2018. T. 88. B. 5. C. 733-739.

DOI: $10.21883 /$ JTF.2018.05.45902.2419

[13] Мальгинов А.В., Кунцевич А.Ю., Мальгинов В.А., Флейшман Л.С. // ЖЭТФ. 2013. Т. 144. В. 6. С. 1225-1238. DOI: $10.7868 / \mathrm{S} 0044451013120110$

[14] Романовский В.Р. // ЖТФ. 2015. Т. 85. В. 1. С. 87-97. 